\title{
EL PROCESO DE TERRITORIALIZACIÓN DEL CAPITAL EN EL CAMPO VENEZOLANO Y EL DESAR- ROLLO SOCIO TERRITORIAL EN VENEZUELA: PRIMERA APROXIMACIÓN
}

\author{
Denir de Oliveira Sosa Jr ${ }^{1}$ \\ ${ }^{1}$ Doctorando en el Doctorado en Desarrollo Social de la Universidad Nacional Experimental Politécnica de la Fuerza Armada Nacional - \\ Caracas Venezuela
}

Recebido em 07/2013. Aceito para publicação em 10/2013.

Versão online publicada em 12/09/2014 (http://seer.ufrgs.br/paraonde)

\begin{abstract}
Resumo - Mesmo considerando que a historia relacionada à ocupação territorial da Venezuela não começa com a chegada dos invasores espanhóis, este artigo centrará esforços em apresentar os fatores econômicos pós colonização, que segundo nossas considerações, colaboraram para definir ou caracterizar sócio-espacialmente o território venezuelano.

As características relacionadas à produção agrícola serão sempre seguidas de uma análise das situações sociais que acarretaram nos esforços para não cair na armadilha de relacionar causa-efeito mas, sim, demonstrar quais os cenários que foram se configurando dentro do agro venezuelano e a relação deste com as formas de produção que foram dominando e configurando territorialmente o estado nação venezuelano.
\end{abstract}

Palavras-chave: : território, territorialização, capital, formas de produção, Venezuela.

\section{Introducción}

El espacio agrario venezolano posterior a 1999 aparece en el escenario nacional como un territorio en disputa, de un lado del cuadrilátero están los antiguos terratenientes, grandes empresas agrícolas (nacionales e internacionales), especuladores inmobiliarios y un incontable número de especuladores e intermediarios relacionados con la compra y venta de alimentos; del otro los movimientos sociales organizados, los pequeños propietarios, los campesinos sin tierra y el Gobierno Nacional, representado por los distintos órganos relacionados a la cuestión agraria y agrícola.

La pregunta es ipor qué disputan un espacio político, económico y territorialmente deprimido? Un observador desapercibido podría considerar que esta contienda no tiene mayor transcendencia que el puro sabor del embate en un país que tiene la gran mayoría de sus ganancias provenientes del petróleo. Si consideramos solamente el factor económico inmediato podríamos dar razón a esta alegación, el punto es que tenemos que ir más allá de las consideraciones de carácter inmediato.

El espacio agrario no debe ser considerado apenas como un lugar de producción y reproducción de capital que, en todo el mundo y para esta discusión en específico en Venezuela, viene desde un largo plazo sufriendo los problemas acarreados por el modo de producción capitalista, más si como un territorio que incorpora los factores jurídico-político, cultural y económico. Según nuestra comprensión, si el análisis no incorpora multifactores, se está propenso a no comprender los complejos meandros del poder que se ocultan por detrás de esta disputa.

Según Raffestin (1993) “...el poder se manifiesta durante la relación. Es un proceso de cambio o comunicación cuando, en la relación que se establece, los dos polos se enfrentan. Las fuerzas que tienen ambos lados (en el caso más simple) establecen un campo: el campo del poder. [...] El campo de la relación es un ámbito de poder que organiza los elementos y las configuraciones".

Podemos afirmar que hasta inicios del siglo XX la economía venezolana estaba basada en la agricultura, e independientemente de sus matices, la tierra en este periodo era considerada explícitamente un sinónimo de riqueza y consecuentemente de poder (tanto económico como político). Las actividades productivas tenían su sustentáculo en: la propiedad privada de la tierra, la mano de obra esclava y en los monocultivos para exportación. En este periodo, resumidamente la sociedad venezolana estaba compuesta por los señores grandes propietarios, los negros o indios esclavos y los mestizos libres (que fatalmente trabajarían en tierras de los grandes propietarios por falta de otra oportunidad).

\section{La Organización Territorial de la Producción: la conformación del Poder Político Económico Nacional}

De una manera general, podemos afirmar que la organización social venezolana desde su invasión en 1492 estuvo a remolque de las posibles ganancias económicas que ella podría proporcionar a la Corona Española, resaltamos que esta característica no era exclusiva de Venezuela, sino de todas las colonias ocupadas por España y Portugal en este periodo histórico.

Otro factor que debe ser considerado es que los abordajes sobre la participación de los indígenas y su 
forma de organización anterior a la llegada de los invasores españoles no tendrá la necesaria profundidad teórica, pues no disponemos en este artículo del tiempo necesario para tal faena, por este motivo en determinados párrafos acudiremos al tema para explicar cómo los pueblos originarios fueron utilizados para territorializar una nueva forma de producción y de sociedad.

\section{La base productiva y las formas de propiedad}

Las primeras actividades económicas de Venezuela fueron caracterizadas por Brito Figueroa (2009, p.61) como sigue:

\begin{abstract}
... diferentes sistemas globales de producción, con características de régimen económico de esclavitud y de relaciones de servidumbre. [...] Los rasgos cualitativos de la estructura económica de Venezuela colonial se destacan a estudiar las primeras actividades económicas, el comercio de esclavos, la formación de la propiedad territorial agraria, la evolución de la mano de obra, la significación del capital usurario y las conexiones de la producción agropecuaria venezolana con el mercado capitalista mundial.
\end{abstract}

El tráfico de esclavos indios, la pesca de perlas y una incipiente minería, sumada a la utilización de los productos ya cultivados por los indígenas en la nueva colonia conquistada (yuca y maíz), fueron las primeras actividades económicas de los invasores españoles en suelo venezolano. (BRITO FIGUEROA, 2009; RINCÓN GUTIERREZ, 2006)

Los relatos históricos demuestran que la demora en descubrir metales preciosos en suelo venezolano llevó a los españoles a búsqueda de otras formas de ocupación del nuevo territorio conquistado, la ganadería y la producción de especies serían las soluciones económicas encontradas por los conquistadores para efectivamente dominar su nueva posesión.

Como ya fue citado anteriormente, las primeras actividades económicas estaban basadas en la grande propiedad, esclavitud primero indígena y después negra y en el monocultivo para exportación.

Cada producto fue dando los matices al área geográfica en donde se fue estableciendo, de esta forma las actividades relacionadas a la producción animal (de grande porte) y las actividades agrícolas para la exportación moldearon el territorio venezolano y consecuentemente orientaron las relaciones sociales en la colonia.

La ganadería ocuparía territorialmente los llanos centro-occidentales en la forma de los "hatos ${ }^{2 "}$ y la agricultura ocuparía la zona septentrional en la forma de "haciendas 3 " y de "plantación ${ }^{4}$ ".

Las formas de explotación agrícola van modificán- dose y "evolucionando" en dirección al trabajo no esclavo (que en numerosos casos beneficiaba más al antiguo Señor que al negro libre). Gutiérrez expone que se acentúa la dualidad macro-microtenencia en la forma de explotación agrícola, de nuestra parte consideramos que las formas en las que el territorio fue ocupado con el pasar de los siglos fue cambiando algunas de sus características, además de eso es importante considerar que nuevas actividades económicas fueron incorporándose al circuito productivo nacional ocasionando así una nueva configuración territorial, pero todas ellas mantuvieron sus características principales: grandes extensiones, producción especializada y marginalización social acentuada.

\section{Dinamismo económico y ocupación territorial}

La dinámica económica fue la que determinó la organización social venezolana. La afirmación se basa en el análisis histórico de los ciclos productivos y la atracción o repulsión que estos causaban (y para nosotros aún hoy causan) en el momento de la ocupación y organización territorial del espacio.

La pesca de perlas, la búsqueda de metales preciosos, la ganadería y la agricultura fueron las actividades que organizaron espacialmente la Venezuela colonial, es importante resaltar que la agricultura fue la actividad que dio mayor estimulo al proceso de poblamiento.

Los espacios eran organizados en pequeños pueblos que a su vez se integraban en redes conectados a pueblos mayores, cada producto dejaba su huella en la organización del espacio, o sea, el cacao formó áreas de población negra en la cuesta del Caribe, Valles Centrales y en el Lago de Maracaibo; el añil estimuló la población en los Valles de Aragua; el café dominó las estribaciones de la Cordillera de la Costa y de Los Andes, etcétera.

Existen algunas características que son constantes en todas estas formas de producción: monoproducción, orientación al mercado externo, dependencia grande de los precios externos y gran dificultad para mantener el rendimiento. Además de eso podemos agregar que el hato sigue siendo una constante en el escenario venezolano.

En contrapartida, en este mismo periodo el desarrollo de la agricultura andina empieza a demostrar algunas características que la diferencian de las demás formas de producción que dominaba el escenario, estas características se referían a la incorporación de tierras inexploradas (nor-occidente), refuerzo de la pequeña propiedad, dinamización de una región deprimida, estímulo a flujos importadores, fortalecimiento de la red urbana andina, introducción de cambios en la forma de vida.

\footnotetext{
${ }^{2}$ Haciendas destinadas a la ganadería extensiva.

${ }^{3}$ Producción variada destinada al consumo directo de la población.

${ }^{4}$ Producción de un solo tipo de cultivo.
} 


\section{Venezuela y el Siglo XX}

En la entrada del siglo XX, Venezuela presentaba características que la mantenían muy similar a su tiempo de colonia, aún en 1926 poseía una población de 2.900.000 de habitantes, una tasa de mortalidad de 16 x 1000 nacidos vivos, la perspectiva de vida era de 38 años, tenía $66 \%$ de analfabetos, 500.000 niños sin escuela, además de poseer $85 \%$ de su población viviendo y trabajando en el medio rural. En la primera década del siglo, la economía agrícola representaba el sustentáculo de economía (70\% del Producto Territorial Bruto y $85 \%$ de las exportaciones).

Es en 1926 cuando el petróleo supera al café (principal producto para exportación) en el renglón de exportaciones, este factor sumado a la gran crisis de 1929 aceleran la decadencia del sector agrícola nacional, llevando a la ruina a los productores nacionales, con eso ocurre una concentración de las propiedades en el medio rural. Otro factor importante es que el papel de la agricultura cambia de agroexportador para una agricultura intensiva tecnificada al servicio de la nueva industria nacional y de la urbanización creciente.

El periodo que va de 1936 a 1957 es que (de forma antagónica) se conforma el Ministerio de Agricultura y Cría, se invierte en las escuelas de agricultura y veterinaria, en cátedras ambulantes de agricultura, la Ley de Reforma Agraria y el Instituto Agrario Nacional, son impulsados los planes azucarero y arrocero, el paquete tecnológico empieza a ser desarrollado en su integra (maquinaria, fertilizantes, insecticidas, herbicidas, semillas "mejoradas"), disminución de mano de obra y uso intensivo de capital.

Los periodos subsecuentes son más angustiantes para el sector agrícola, ya que entre las medidas tomadas en el ámbito económico estaban la eliminación de los subsidios para fertilizantes, disminución de los gastos públicos agrícolas, disminución de aproximadamente $30 \%$ en los créditos agrícolas. Tales medidas ocasionan la disminución de la producción, colapso en el mercadeo público y disminución en la superficie cosechada.

Creemos que no es erróneo afirmar que a partir de las primeras décadas del siglo XX empieza un desmonte del sector agrícola nacional, un cambio tan radical que en vez de colocar la agricultura y la pecuaria como coadyuvantes en el escenario económico nacional, él casi destruye los antiguos sustentáculos económicos del país.

Aún cuando no se abordó con la profundidad necesaria en este artículo, queda claro que es con el ascenso del petróleo a partir de 1926, que empieza la caída abrupta de las actividades agropecuarias en Venezuela.

Un ejemplo claro es cuando hacemos el análisis de la participación del ingreso petrolero en el presupuesto nacional durante los años veinte:

\begin{tabular}{c|c|c} 
Año & $\begin{array}{c}\text { Exportaciones } \\
\text { Petroleras } \\
\text { (miles de bolívares) }\end{array}$ & $\begin{array}{c}\text { Porcentaje del } \\
\text { ingreso nacional }\end{array}$ \\
\hline 1918 & 899,6 & $0,20 \%$ \\
\hline 1920 & $5.261,3$ & $0,96 \%$ \\
\hline 1924 & $101.020,3$ & $12,52 \%$ \\
\hline 1926 & $259.147,4$ & $21,35 \%$ \\
\hline 1928 & $466.942,1$ & $30,64 \%$ \\
\hline 1930 & $634.055,7$ & $45,38 \%$
\end{tabular}

Fuente: Veloz, Ramón. Economía y Finanzas de Venezuela. In VILLALBA, J. (1981). Industria. Caracas: Armitano - C.A. Cigarrera Bigott Sucs, p.24.

A lo largo de los periodos del siglo XX ocurrió una pérdida visiblemente acentuada de importancia de la forma de producción relacionada al sector agroexportador frente a la minero rentista, pero un factor aparece como inmutable en el escenario agrario venezolano: "la predominancia de la gran propiedad de carácter latifundista", esta fue la forma en que los antiguos poderosos latifundistas elegirían para mantenerse a flote en la nueva sociedad que estaba siendo gestada a partir de la nueva forma de producción vinculada a la extracción petrolera.

La gran propiedad, aunque con una baja inversión, mantendría de manera débil el estatus "quo" de las antiguas familias aristócratas venezolanas, lo cual proporcionó que determinadas áreas del país fuesen vistas como el lugar por excelencia de esa forma de producción, lo que a su vez proporcionó la creación de las áreas de depresión económica y social dentro del territorio nacional.

En algunos casos en donde el proceso productivo en la gran propiedad es seguido de alguna forma de inversión (paquete tecnológico), los reflejos en la calidad de vida del trabajador no son percibidos, además de eso como el proceso tecnológico utilizado es, en su gran mayoría adquirido en circuitos externos a las fronteras regionales, estadales y en la mayoría de los casos nacionales, ocurre una fuga de inversiones para otros estados del país, proporcionando pérdidas en la localidad donde es desarrollada la actividad productiva en específico.

Los factores que indican el retraso socio económico de las localidades que tienen como característica el latifundio rentista como forma de producción predominante son: el bajo nivel económico de la mayoría de su población; bajos niveles de educación; alta tasa de empleo temporario (jornalero); presencia de poca infraestructura de los órganos estadales (debido a su dinámica de reproducción lenta) en sus estructuras de carreteras, y cuando la había era conectada directamente la actividad de producción a la vía principal más próxima; incapacidad de generar procesos virtuosos de distribución de renta y de integración de la mayor parte de la población local en los procesos productivos locales; y baja transformación de los productos producidos en ámbito local.

En una rápida comparación entre formas de pro- 
ducción agropecuaria apoyadas en la pequeña propiedad (diversificada) y en el latifundio (pecuario o monoproductor agrícola), son perceptibles las dinámicas socioterritoriales que cada una de ellas deja en el espacio venezolano.

Es importante resaltar que la manutención de una forma de producción o de una actividad que claramente tiene grandes dificultades en proporcionar un proceso de desarrollo igualitario, tanto económico como político y social de una determinada colectividad, no es obra del azar o de alguna fuerza divinal, tal proceso hace parte de una estrategia de territorialización del capital y de dominio político económico de las áreas "deprimidas" por parte de grupos que fueron gradualmente perdiendo su importancia económica y política nacional, más que intentan de una manera o de otra mantener su poder (al menos político) regionalmente.

Algunos puntos quedan como interrogantes, posterior el análisis de los factores arriba presentados, estos se refieren a: ¿de qué forma serán impulsadas las actividades productivas en el agro venezolano a partir del escenario político posterior a 1999?, ¿las formas de producción que tienen como base la gran propiedad están sentenciadas a la extinción o tendrán un espacio en este nuevo escenario?, y ¿cómo serán tratados los intereses políticos regionales?

\section{Buscando las Reflexiones Finales}

Como fue posible observar, están íntimamente relacionados los factores económicos y sociales en la conformación y configuración del espacio agrario venezolano, por este motivo consideramos que la organización del territorio debe estar basada en la organización del factor económico para poder, a partir de ahí, de forma concomitante desarrollar el factor social.

En nuestro entendimiento uno de los principales cambios que debe ocurrir para dinamizar el agro venezolano está relacionado con la cuestión de la tenencia de la tierra, este es un punto clave para el desarrollo de políticas económicas socialmente incluyentes. Está comprobado que las pequeñas y medianas propiedades tienen una tasa de productividad y rentabilidad superior a la gran propiedad monocultora, además de estar menos propensas a pérdidas totales, debido a su característica de diversificación productiva. Es necesario explicar que con esta afirmación no estamos proponiendo la división del territorio venezolano en minifundios de una manera arbitraria y tampoco que esta forma de propiedad resolvería todos los problemas que hoy tenemos en el agro, lo que consideramos es que se debe avanzar en dirección a nuevas estructuras de propiedad productiva, tomando en consideración que las formas basadas en la gran propiedad capitalista vienen demostrando históricamente su incapacidad de coadunar los factores económico y social de forma más o menos armónica.

Uno de los factores a considerar en las propues- tas referentes a la forma de producción para el agro venezolano están contenidos en la afirmación de Troudi (2010, p. 84), cuando nos enseña que " ... la política económica del Gobierno Bolivariano a la fecha se ha caracterizado por un eclecticismo pragmático (mezcla de monetarismo liberal, relaciones de producción del tipo capitalista de estado, aperturismo del tipo socialismo de mercado y nueva experimentación económica vía participación productiva de las comunidades, etc.)...." Este factor complica aún más el escenario, pues caminar por una ruta tan diversa torna todos los esfuerzos de transformación en una tarea hercúlea, también TROUDI presenta cuales son las características de las relaciones sociales y los aspectos que debemos considerar en las propuestas formuladas para el sector económico nacional (y por consiguiente para el sector agrario), según él es necesario considerar:

Nuevas modalidades de propiedad o posesión de los medios de producción;

Nuevas formas de división del trabajo;

Compromiso con la eficiencia, la productividad y la calidad;

Gestión democrática de los procesos económicos; Conciencia ecológica;

A su vez, los aspectos presentados podrían expresarse en diversas formas de propiedad, entre ellas están la:

Propiedad Pública;

Propiedad Privada;

Propiedad Mixta;

Parafraseando al autor, concordamos en que las formas empresariales y productivas deben apuntalar hacia relaciones de producción socialistas (con sus distintos matices), y que éstas pueden estar contempladas en las:

Empresas de Producción Social (privadas);

Empresas de Propiedad Social (públicas);

Empresas de Producción Socialista (públicas estadales y comunitarias);

Empresas Comunales (comunales);

Cooperativas (privadas, comunitarias);

Unidades de Producción (públicas, privadas, comunitarias), etc.

Todos estos aspectos deben estar asociados a un fuerte esfuerzo de formación de valores socialistas, capacitación técnica, formación académica y profesional, en vista del nuevo modelo productivo y social que se está proyectando, en resumen, una formación técnico-política consistente.

En este escenario, podemos y debemos ubicar el espacio agrario venezolano, pues solamente con la introducción de nuevas formas de producción, es que podremos contrarrestar el poder que aún reposa en los grandes latifundios y que dejan su sello en el territorio y en la sociedad venezolana. 


\section{Bibliografía}

FIGUEROA, F. B. . Historia Economica y Social de Venezuela. ( $7^{\circ}$ ed., Vol. I). Caracas: Ediciones de la Biblioteca - UCV, 2009.

GUTIÉRREZ, P. R. Cátedra: organización del territorio. Recuperado el 28 de Octubre de 2010, de ULA, diciembre de 2006.

HAESBAERT, R. Da desterritorializacao a multiterritorialidade. En En Anais do IX Encontro da ANPUR (Vol. Vol.3). Rio de Janeiro, 2001.

RAFFESTIN, C. Por uma geografia do poder. (M. Franca, Trad.) Sao Paulo: Atica, 1993.

TROUDI, H. E. La Politica Económica Bolivariana (PEB). Caracas: Monte Ávila, 2010.

VILLALBA, J. Industria. Caracas: Armitano. C.A. Cigarrera Bigott Sucs, 1981. 